\title{
Phylogenetic Analysis of the Genus Desulfotomaculum: Evidence for the Misclassification of Desulfotomaculum guttoideum and Description of Desulfotomaculum orientis as Desulfosporosinus orientis gen. nov., comb. nov.

\author{
ERKO STACKEBRANDT, ${ }^{*}$ CATHRIN SPROER, FREDERICK A. RAINEY, JUTTA BURGHARDT,
} ORSOLA PÄUKER, AND HANS HIPPE
}

DSMZ-Deutsche Sammlung von Mikroorganismen und Zellkulturen, 38124 Braunschweig, Germany

\begin{abstract}
Almost complete 16S ribosomal DNA (rDNA) sequences were determined for the type strains of nine species belonging to the genus Desulfotomaculum and for seven strains described as strains of this genus. The sequences were compared with previously published 16S rDNA and rRNA sequences of the type strains of the other species of the genus. The majority of the species form a phylogenetically coherent cluster within the Clostridium-Bacillus subphylum of gram-positive bacteria. The cluster consists of phylogenetically well-separated lineages containing (i) Desulfotomaculum nigrificans, Desulfotomaculum aeronauticum, and Desulfotomaculum ruminis, (ii) Desulfotomaculum geothermicum, Desulfotomaculum thermosapovorans, and Desulfotomaculum sapomandens, (iii) Desulfotomaculum kuznetsovii, Desulfotomaculum australicum, and Desulfotomaculum thermocisternum, (iv) Desulfotomaculum thermobenzoicum and Desulfotomaculum thermoacetoxidans, and (v) Desulfotomaculum acetoxidans. Some as-yet-undescribed Desulfotomaculum strains are phylogenetically well-separated from strains of the described species. Desulfotomaculum guttoideum shares extremely high 16S rDNA similarity with certain Clostridium species (e.g., Clostridium sphenoides and Clostridium celerecrescens) and is most likely a misidentified species. Desulfotomaculum orientis represents a new genus which branches most closely to the genus Desulfitobacterium. The name Desulfosporosinus orientis gen. nov., comb. nov., is proposed for this taxon.
\end{abstract}

The genus Desulfotomaculum comprises 15 validly described species, more than half of which have been described during the past 7 years. The majority of the more recently described species originate from thermal environmental sites which are presently among the prime habitats in the search for novel prokaryotic biodiversity (38).

Although several Desulfotomaculum species show gram-negative staining behavior, their cell walls possess the typical ultrastructure of gram-positive bacteria $(29,36)$. Species are defined by sulfate reduction and the presence of spores, but the shape of spores (spherical to oval) and the location of spores (central, subterminal, or terminal) vary. Desulfotomaculum species differ from each other in physiology; e.g., some species are autotrophic, while others grow by fermentation of glucose and other organic substrates. A few species perform homoacetogenesis by converting substrates, such as $\mathrm{H}_{2}$ plus $\mathrm{CO}_{2}$ and a few others, to acetate $(24,44)$.

Several studies involving comparative sequence analysis of $16 \mathrm{~S}$ rRNA and $16 \mathrm{~S}$ ribosomal DNA (rDNA) have shown that Desulfotomaculum species are related to members of the Clostridium-Bacillus subphylum $(4,9,10,16,38)$. However, fine details concerning the phylogenetic coherence of this genus and the relatedness of its species have not yet been fully explored. Most previous studies included only a few species, and even the most recently published phylogenetic trees did not include more than eight or nine species $(14,18,31)$. These studies showed that the majority of species cluster together to form a major subline of descent among the several clusters encompassing clostridia and their non-spore-forming and/or coccoid relatives (4). Consistently, the main Desulfotomaculum

\footnotetext{
* Corresponding author. Mailing address: DSMZ-Deutsche Sammlung von Mikroorganismen und Zellkulturen, Mascheroder Weg 1B, 38124 Braunschweig, Germany. Phone: 495312616 352. Fax: 49 5312616 418. E-mail: erko@gbf-braunschweig.de.
}

species cluster adjacent to members of the genera Moorella, Thermoanaerobacterium, and Thermoanaerobacter. In contrast, Desulfotomaculum orientis branched outside the main Desulfotomaculum cluster, showing moderate relatedness to members of the genus Desulfitobacterium $(31,42)$. However, the branching order of higher taxa within the Clostridium-Bacillus subphylum has not yet been unambiguously determined, because certain factors affect the branching pattern of lineages; these factors include the selection and number of reference organisms, the length of the sequences included in the analysis and the regions of the molecule compared, differences in the DNA base compositions of rDNA from mesophilic and thermophilic species, and the quality of the sequences in the database, which is related to the various sequencing approaches used (32). The classification of the genus Clostridium and its relatives (e.g., the genera Peptococcus, Eubacterium, Ruminococcus, and Bacillus) is presently undergoing a dramatic revision which is based on the results of comparative $16 \mathrm{~S}$ rDNA sequence analyses. In this paper we describe the phylogenetic relatedness of the type strains of all available species of the genus Desulfotomaculum and some undescribed strains of this genus; our data led to the conclusion that, with two exceptions, the results of phylogenetic analysis match the phenotype-based classification of $D e$ sulfotomaculum species.

\section{MATERIALS AND METHODS}

Bacterial strains. The strains analyzed in this study, their growth media, and their growth temperatures $(11,12)$ are listed in Table 1 . All strains were cultivated anaerobically as described previously $(11,12)$.

16S rDNA sequence determination and analysis. Genomic DNAs were extracted from the strains investigated in this study and were used for PCRmediated amplification of $16 \mathrm{~S}$ rDNA (34). The purified PCR products were cloned, the $16 \mathrm{~S}$ rDNA inserts were reamplified and sequenced as described previously (33), and the sequence reaction mixtures were electrophoresed by using a model 373A automatic DNA sequencer (Applied Biosystems, Foster City, Calif.).

In order to analyze the closest relatives of Desulfotomaculum strains, their 
TABLE 1. Strains investigated in this study, growth media, growth temperatures, $\mathrm{G}+\mathrm{C}$ contents of rDNAs, and references

\begin{tabular}{|c|c|c|c|c|c|}
\hline Taxon & Strain & $\begin{array}{l}\text { Growth } \\
\text { medium }^{a}\end{array}$ & $\begin{array}{l}\text { Growth temp } \\
\left({ }^{\circ} \mathrm{C}\right)\end{array}$ & $\begin{array}{l}\mathrm{G}+\mathrm{C} \text { content of } \\
\text { rDNA }(\mathrm{mol} \%)\end{array}$ & Reference \\
\hline Desulfotomaculum acetoxidans & DSM $771^{\mathrm{T}}$ & 124 & 37 & 53.4 & 45 \\
\hline Desulfotomaculum geothermicum & DSM $3669^{\mathrm{T}}$ & 406 & 50 & 57.8 & 6 \\
\hline Desulfotomaculum guttoideum & DSM $4024^{\mathrm{T}}$ & 63 & 30 & 54.0 & 17 \\
\hline Desulfotomaculum kuznetsovii & DSM $6115^{\mathrm{T}}$ & 63 & 60 & 59.1 & 28 \\
\hline Desulfotomaculum orientis & DSM $765^{\mathrm{T}}$ & 63 & 30 & 55.0 & 3 \\
\hline Desulfotomaculum orientis & DSM 8344 & 641 & 30 & 54.1 & 43 \\
\hline Desulfotomaculum ruminis & DSM $2154^{\mathrm{T}}$ & 63 & 37 & 54.9 & 3 \\
\hline Desulfotomaculum thermoacetoxidans & DSM $5813^{\mathrm{T}}$ & 63 & 60 & 58.9 & 27 \\
\hline Desulfotomaculum thermobenzoicum & DSM $6193^{\mathrm{T}}$ & 63 & 60 & 59.3 & 41 \\
\hline Desulfotomaculum thermosapovorans & DSM $6562^{\mathrm{T}}$ & 667 & 50 & 58.0 & 14 \\
\hline Desulfotomaculum sp. & DSM 7213 & $124 a$ & 35 & 54.8 & 12 \\
\hline Desulfotomaculum sp. & DSM 7440 & 63 & 50 & 54.8 & 12 \\
\hline Desulfotomaculum sp. & DSM 7474 & 682 & 55 & 58.3 & 40 \\
\hline Desulfotomaculum sp. & DSM 7475 & 682 & 55 & 57.9 & 40 \\
\hline Desulfotomaculum sp. & DSM 7476 & 682 & 55 & 58.5 & 40 \\
\hline
\end{tabular}

\footnotetext{
${ }^{a}$ Growth media are described in references 11 and 12 .
}

phylogenetic positions were initially determined by using the database ARB (39). Fine resolution of the relatedness between Desulfotomaculum strains and their closest relatives was obtained by using the ae2 editor (26). Phylogenetic dendrograms were reconstructed by using treeing algorithms contained in the PHYLIP package (15). The $\mathrm{G}+\mathrm{C}$ contents of rDNA genes were calculated and a transversion analysis was done as described previously (32). Bootstrap values were determined by using the PHYLIP package (15). The accession numbers for the $16 \mathrm{~S}$ rDNA sequences of reference organisms were as follows: Ammonifex degensii, U34975; Clostridium sphenoides, X73449; Clostridium celerecrescens, X71848; Clostridium aerotolerans, X76163; Clostridium xylanolyticum, X71855; Desulfitobacterium dehalogenans, L28946; Desulfitobacterium hafniense, X94975; Desulfotomaculum aeronauticum, X98407; Desulfotomaculum australicum, M96665; Desulfotomaculum nigrificans, X62176; Desulfotomaculum thermocisternum, U33455; Heliobacterium chlorum, M11212; Moorella thermoautotrophica, X77849; Peptococcus niger, X55797; Thermoanaerobacter ethanolicus, L09162; Thermoanaerobacter thermocopriae, L09167; and Thermoanaerobacterium saccharolyticum, L09169. The sequences of Desulfotomaculum sapomandens, Syntrophospora bryantii, and Selenomonas sputigena were obtained from the Ribosomal Database Project (26).

DNA isolation and characterization. Isolation of DNA and DNA-DNA hybridization $(7,13)$, as well as determination of renaturation rates $(21,22)$, were performed as previously described.

Nucleotide sequence accession numbers. The 16S rDNA sequences determined have been deposited in the EMBL database under the following accession numbers: Desulfotomaculum acetoxidans DSM 771 ${ }^{\mathrm{T}}$, Y11566; Desulfotomaculum geothermicum DSM 3669 ${ }^{\mathrm{T}}$, Y11567; Desulfotomaculum guttoideum DSM 4024 ${ }^{\mathrm{T}}$, Y11568; Desulfotomaculum kuznetsovii DSM 6115 ${ }^{\mathrm{T}}$, Y11569; Desulfotomaculum orientis DSM $765^{\mathrm{T}}$, Y11570; Desulfotomaculum orientis DSM 8344, Y11571; Desulfotomaculum ruminis DSM 2154 ${ }^{\mathrm{T}}$, Y11572; Desulfotomaculum thermoacetoxidans DSM 5813 ${ }^{\mathrm{T}}$, Y11573; Desulfotomaculum thermobenzoicum DSM $6193^{\mathrm{T}}$, Y11574; Desulfotomaculum thermosapovorans DSM 6562 ${ }^{\mathrm{T}}$, Y11575; and Desulfotomaculum sp. strains DSM 7213, DSM 7440, DSM 7474, DSM 7475, and DSM 7476, Y11576, Y11579, Y11577, Y11580, and Y11578, respectively.

\section{RESULTS AND DISCUSSION}

All presently available type strains of Desulfotomaculum species were included in this study. The type strain of Desulfotomaculum antarcticum (3) was originally deposited as strain IAM 64 in the culture collection of the Institute of Applied Microbiology, Tokyo, Japan. According to the curator of this collection, the strain deposited under this designation is not a Desulfotomaculum strain, and as we are not aware that the type strain has been deposited in any other collection, it must be considered lost.

$16 S$ rDNA sequence analysis. It became apparent during the sequence analysis of the $16 \mathrm{~S}$ rDNAs of Desulfotomaculum species that the sequence of the $5^{\prime}$-terminal 110 nucleotides (Escherichia coli nomenclature [1]) could not be resolved, irrespective of whether primer $27 \mathrm{f}$ or primer $343 \mathrm{r}$ (33) was used in the cycle sequencing reaction. In order to obtain unambig- uous sequences, the products of PCR amplification of $16 \mathrm{~S}$ rDNAs of 10 strains were cloned. Between three and eight cloned 16S rDNA inserts per strain were sequenced. A sequence analysis of the cloned genes allowed clear resolution of the primary structure of the clone inserts. Several strains possessed large inserts in helical region 73-82/87-97 of the rDNA (47). The primary structure of these intervening sequences and their fate in transcription of rRNA genes will be discussed elsewhere (37). Because of this strain-specific sequence heterogeneity of operons and the fact that many $16 \mathrm{~S}$ rDNA reference sequences deposited in the data banks $(26,39)$ have high degrees of sequence ambiguity (denoted by Ns in the sequences), the region between positions 80 and 100 was omitted from the phylogenetic analysis.

Phylogenetic analysis. The lengths of the $16 \mathrm{~S}$ rDNA sequences of the Desulfotomaculum strains analyzed ranged between 1,350 and 1,450 nucleotides. These sequences were compared to the data set containing clostridial 16S rDNA sequences, and the tentative phylogenetic position of Desulfotomaculum strains was determined by parsimony analysis (38). Subsequent analyses, in which we used the ae 2 editor (26) and the programs contained in the PHYLIP package (15), included neighbor-joining (35) and maximum-parsimony analyses and an analysis with the distance matrix algorithm of De Soete (8). After inclusion of reference sequences of strains of neighboring taxa and omission of the 73-97 region, a stretch of 1,125 nucleotides, ranging from position 65 to position 1450 , was used to determine sequence similarities. All of the analyses produced very similar patterns of relatedness for the Desulfotomaculum strains, which were found in three distinct lineages, designated clusters I to III below. These clusters were recovered in a high proportion of the trees generated, as demonstrated by the bootstrap values for the groups.

The base compositions of the 16S rDNA stretch sequenced indicated that certain thermophilic representatives of the strains analyzed had $\mathrm{G}+\mathrm{C}$ contents that were about 3 to 5 mol\% higher than the $\mathrm{G}+\mathrm{C}$ contents of mesophilic strains and certain other thermophilic strains (Table 1). In order to exclude a $\mathrm{G}+\mathrm{C}$ bias that distorts the relatedness determination, a transversion data set was analyzed by using the method of De Soete (8) and the neighbor-joining method (15). The dendrograms of relationships were very similar except for the branch point of $A$. degensii (20). While the $A$. degensii sequence branched within the radiation of cluster I Desulfotomaculum 


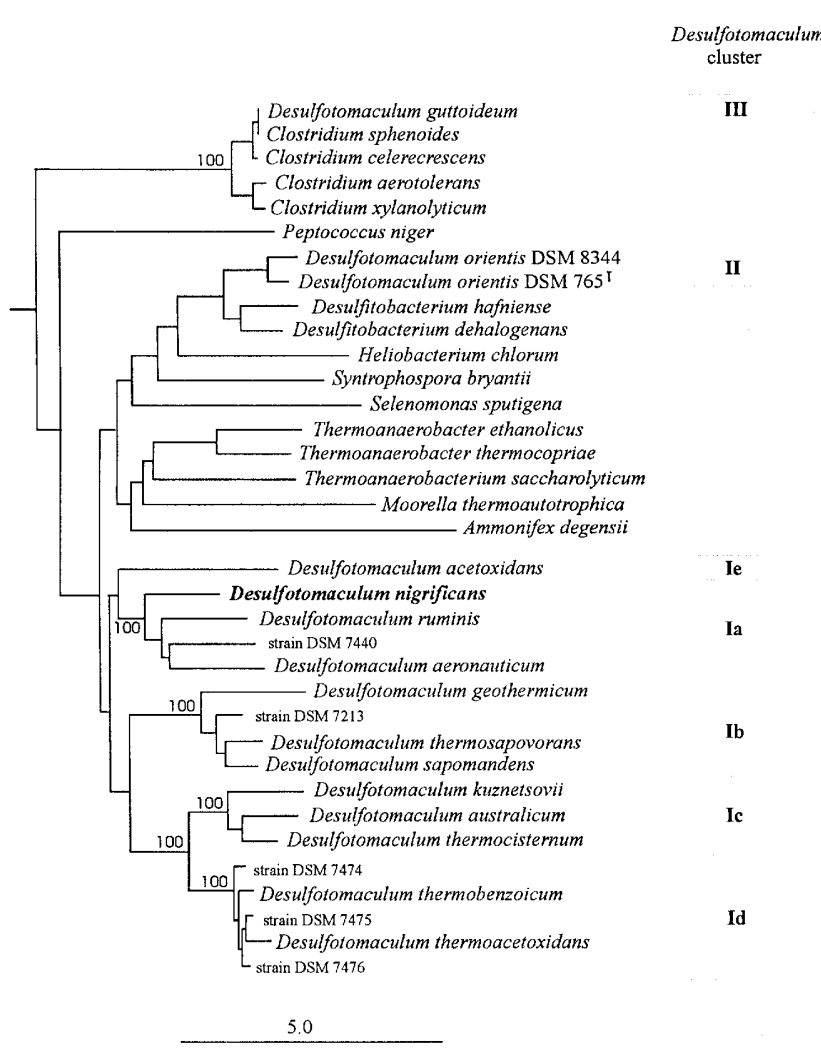

FIG. 1. Phylogenetic dendrogram based on the results of $16 \mathrm{~S}$ rDNA sequence comparisons. The neighbor-joining tree was derived from transversion distances. Roman numerals indicate several clusters and subclusters of the $D e$ sulfotomaculum species and strains investigated. Bootstrap values (expressed as percentages of 500 replications) are shown at the branch points; values greater than $95 \%$ were considered significant. Bar $=5$ nucleotide substitutions per 100 nucleotides.

strains on all dendrograms (with bootstrap values of less than $10 \%$ [data not shown]), on the neighbor-joining tree $A$. degensii was rooted deeply with members of the genus Moorella. As the intrageneric clustering of Desulfotomaculum strains was not affected by this switch in branching, we decided to present the phylogenetic clustering of Desulfotomaculum strains as a result of the transversion neighbor-joining analysis (Fig. 1). The basis for this dendrogram was the similarity values for the transversed sequences, which were transformed to evolutionary distance values (23).

Similarity values of 83 and $90 \%$ separate members of the three clusters. These values are similar to those found to separate other phylogenetically well-separated lineages from each other, including the Selenomonas-Sporomusa group, the Thermoanaerobacter group, and the several lineages composed of clostridia and their relatives (Fig. 1) (4).

Cluster I. Cluster I includes the majority of the Desulfotomaculum species. This cluster is characterized by the presence of five subclusters (subclusters Ia through Ie), most of which are well-separated by similarity values between 89 and $93 \%$. Within the multistrain subclusters the similarity values were greater than $95.5 \%$. The phylogenetic depths of the individual subclusters are different; while subclusters Ia and Ie contain one to several slightly deeply branching strains (separated by similarity values of 94 to $96 \%$ ), subclusters Ib, Ic, and Id are more shallow (with strains having similarity values greater than $98 \%$ ). Subcluster Ia contains the type species of the genus, Desulfotomaculum nigrificans (3), as well as Desulfotomaculum ruminis (3), Desulfotomaculum aeronauticum (18), and strain DSM 7440 (12); these organisms have rather low rDNA G+C contents $(54.5$ to $55.5 \mathrm{~mol} \%)$. Subcluster Ib contains the type strains of Desulfotomaculum sapomandens (5) and Desulfotomaculum thermosapovorans (14) and strain 7213 (12). Desulfotomaculum geothermicum (6) branches slightly deeper than these three strains; members of this subcluster are defined by rDNA $\mathrm{G}+\mathrm{C}$ contents of 55.5 to 58.0 mol\%. Subcluster Ic contains Desulfotomaculum australicum (25), Desulfotomaculum thermocisternum (31), and Desulfotomaculum kuznetsovii (29), while Desulfotomaculum thermoacetoxidans (27), Desulfotomaculum thermobenzoicum (41), and strains DSM 7474, DSM 7475, and DSM 7476 (40) constitute subcluster Id. The latter two subclusters appear to be closely related (similarity values, more than 97\%), and all members have $\mathrm{G}+\mathrm{C}$ contents of 58.5 to $59.5 \mathrm{~mol} \%$. So far, subcluster Ie is defined solely by Desulfotomaculum acetoxidans (45), which has an rDNA G $+\mathrm{C}$ content of $53.5 \mathrm{~mol} \%$.

In order to support the affiliation of strains with the individual subclusters, the $16 \mathrm{~S}$ rDNA data set was searched for the presence of subcluster-specific signature nucleotides (Table 2). These signature nucleotides are derivatives of the clustering process; e.g., signatures are determined for those organisms that are contained in a particular data set. Subclusters Ia, Ib, and Ie can be defined by a significant number of signature nucleotides, while subclusters Ic and Id have a high number of common signature nucleotides (29 of 33 signature nucleotides). These two subclusters could therefore be regarded as a single subcluster. It is also obvious that Desulfotomaculum geothermicum should be considered a member of subcluster Id, as this organism has 28 of the 33 signature nucleotides of this subcluster. Compared to the sequences of members of the other subclusters, the sequence of Desulfotomaculum acetoxidans is also characterized by longer stems in regions 200-217 (an additional $12 \mathrm{bp}$ ) and 455-477 (an additional $6 \mathrm{bp}$ ). These sequence idiosyncrasies are also present in most members of the sister taxon of Desulfotomaculum cluster I, which contains the genera Desulfitobacterium, Moorella, Ammonifex, and Selenomonas and their relatives. The structural peculiarities may be an indication that Desulfotomaculum acetoxidans could be considered a descendant of the most ancient Desulfotomaculum species that originated from a non-sulfate-reducing ancestor; this possibility is supported by the position of this organism on the phylogenetic tree, on which Desulfotomaculum acetoxidans appears to branch earlier than the other Desulfotomaculum species.

Cluster II. Cluster II contains two strains of Desulfotomaculum orientis which show $98.8 \% 16 \mathrm{~S}$ rDNA sequence similarity to each other. The DNA reassociation value for type strain DSM 765 (3) and DSM 8344 (43) is 39\%, which clearly indicates the presence of two genomospecies. At present, the lack of distinguishing phenotypic properties prevents us from describing a new species for Desulfotomaculum orientis DSM 8344. Strains of Desulfotomaculum orientis are moderately related to members of the genus Desulfitobacterium (42), with which they exhibit between 95.0 and $95.7 \%$ sequence similarity. Desulfotomaculum orientis and the genus Desulfitobacterium form a separate subline of descent within the ClostridiumBacillus subphylum (20). Reinvestigation of physiological properties of the type strain of Desulfotomaculum orientis (24) led to the unexpected finding that this species, in contrast to the other Desulfotomaculum strains investigated in the study of Klemps et al. (24), was able to grow chemoautotrophically with hydrogen, carbon dioxide, and sulfate. It was also able to grow in the absence of sulfate with formate, methanol, ethanol, 
TABLE 2. 16S rDNA signature nucleotides in Desulfotomaculum subclusters Ia through Ie

\begin{tabular}{|c|c|c|c|c|c|c|}
\hline \multirow[b]{2}{*}{ Position(s) } & \multicolumn{6}{|c|}{ Signature nucleotide(s) in: } \\
\hline & $\begin{array}{l}\text { Subcluster Ia } \\
\text { (5 strains) }\end{array}$ & $\begin{array}{l}\text { Subcluster Ib } \\
\text { (3 strains) }\end{array}$ & $\begin{array}{l}\text { Desulfotomaculum } \\
\text { geothermicum }\end{array}$ & $\begin{array}{l}\text { Subcluster Ic } \\
\text { (3 strains) }\end{array}$ & $\begin{array}{l}\text { Subcluster Id } \\
\text { (5 strains) }\end{array}$ & $\begin{array}{c}\text { Subcluster Ie } \\
\text { (Desulfotomaculum } \\
\text { acetoxidans) }\end{array}$ \\
\hline $45-396$ & U-A & U-A & U-A & U-A & U-G & U-A \\
\hline $154-167$ & $A-U$ & G-U & G-U & G-Pyr & G-Pyr & G-U \\
\hline $155-166$ & $\mathrm{G}-\mathrm{C}$ & $\mathrm{C}-\mathrm{G}$ & U-G & $\mathrm{C}-\mathrm{G}$ & $\mathrm{C}-\mathrm{G}$ & C-G \\
\hline $138-225$ & G-C & $A-U$ & A-U & $A-U$ & $A-U$ & $\mathrm{~A}-\mathrm{U}$ \\
\hline $259-267$ & U-A & $\mathrm{G}-\mathrm{C}$ & G-C & $\mathrm{G}-\mathrm{C}$ & $\mathrm{G}-\mathrm{C}$ & $\mathrm{G}-\mathrm{C}$ \\
\hline $252-274$ & U-A & U-A & U-A & A-U & $A-U$ & U-A \\
\hline 293-304 & G-C & $\mathrm{G}-\mathrm{C}$ & $\mathrm{G}-\mathrm{C}$ & $\mathrm{G}-\mathrm{U}$ & G-U & G-U \\
\hline $320-333$ & C-G & U-A & U-A & C-G & C-G & U-A \\
\hline 381 & A & $\mathrm{C}$ & $\mathrm{C}$ & A & A & A \\
\hline $409-433$ & G-C & U-A & C-G & $\mathrm{C}-\mathrm{G}$ & C-G & C-G \\
\hline $444-490$ & $\mathrm{~A}-\mathrm{U}$ & A-U & $\mathrm{G}-\mathrm{C}$ & $\mathrm{G}-\mathrm{C}$ & $\mathrm{G}-\mathrm{C}$ & U-A \\
\hline 449 & A & A & A & A & $\mathrm{C}$ & $\mathrm{C}$ \\
\hline 534 & A & A & A & $\mathrm{G}$ & G & U \\
\hline $586-755$ & U-A & $\mathrm{C}-\mathrm{G}$ & $\mathrm{C}-\mathrm{G}$ & C-G & C-G & C-G \\
\hline $593-646$ & U-G & G-C & G-C & $\mathrm{A}-\mathrm{U}$ & $\mathrm{A}-\mathrm{U}$ & U-G \\
\hline $596-644$ & A-U & A-U & $A-U$ & $A \cdot C$ & $A \cdot C$ & $\mathrm{~A}-\mathrm{U}$ \\
\hline 610 & $\mathrm{G}$ & $\mathrm{C}$ & C & $\mathrm{U}$ & $\mathrm{U}$ & A \\
\hline $657-749$ & U-A & U-A & U-A & $\mathrm{G}-\mathrm{C}$ & $\mathrm{G}-\mathrm{C}$ & U-A \\
\hline $662-743$ & $\mathrm{G} \cdot \mathrm{A}$ & $\mathrm{U} \cdot \mathrm{C}$ & G-C & G-C & G-C & $\mathrm{G}-\mathrm{C}$ \\
\hline $672-734$ & C-G & U-G & U-G & U-G & U-G & U-G \\
\hline $682-708$ & $\mathrm{~A}-\mathrm{U}$ & A-U & A-U & G-C & G-C & $\mathrm{A}-\mathrm{U}$ \\
\hline $668-738$ & G-U & $\mathrm{G}-\mathrm{C}$ & $\mathrm{G}-\mathrm{C}$ & G-U & $\mathrm{G}-\mathrm{U}$ & $\mathrm{G}-\mathrm{C}$ \\
\hline 730 & $\mathrm{G}$ & A & A & $\mathrm{G}$ & $\mathrm{G}$ & $\mathrm{G}$ \\
\hline $822-878$ & A-U & $\mathrm{G}-\mathrm{C}$ & G-C & $\mathrm{G}-\mathrm{C}$ & $\mathrm{G}-\mathrm{C}$ & $\mathrm{G}-\mathrm{C}$ \\
\hline $896-903$ & U-A & C-G & C-G & C-G & C-G & U-A \\
\hline $948-1233$ & U-A & U-A & C-G & $C-G$ & $\mathrm{C}-\mathrm{G}$ & U-A \\
\hline 989-1216 & G-U & U-A & U-A & G-U & $\mathrm{G}-\mathrm{U}$ & G-U \\
\hline 1118-1155 & $\mathrm{A}-\mathrm{U}$ & C-G & C-G & C-G & $C-G$ & C-G \\
\hline $1120-1153$ & A-U & U-A & U-A & $\mathrm{G}-\mathrm{C}$ & $\mathrm{G}-\mathrm{C}$ & $\mathrm{G}-\mathrm{C}$ \\
\hline $1129-1143$ & $C-G$ & $C-G$ & C-G & U-A & C-G & C-G \\
\hline $1047-1210$ & $\mathrm{G}-\mathrm{C}$ & $\mathrm{G}-\mathrm{U}$ & $\mathrm{G}-\mathrm{U}$ & $\mathrm{G}-\mathrm{C}$ & G-U & $\mathrm{G}-\mathrm{C}$ \\
\hline $1253-1284$ & $C-G$ & C-G & $C-G$ & G-C & $\mathrm{G}-\mathrm{C}$ & $\mathrm{G}-\mathrm{C}$ \\
\hline $1310-1327$ & U-A & $\mathrm{C}-\mathrm{G}$ & C-G & C-G & C-G & U-A \\
\hline
\end{tabular}

lactate, pyruvate, or trimethoxybenzoate. It was concluded on the basis of the formation of acetate that this species can be considered a homoacetogenic bacterium.

Cluster III. Cluster III is composed of Desulfotomaculum guttoideum DSM $4024^{\mathrm{T}}$ (17). This species is highly related to certain members of Clostridium cluster XIVa, as defined by Collins and coworkers (4). When we used the truncated 16S rDNA sequences that were used to determine the relatedness shown in Fig. 1, the similarity values found for Desulfotomaculum guttoideum and $C$. sphenoides, $C$. celerecrescens, $C$. aerotolerans, and $C$. xylanolyticum were greater than $98.5 \%$. When almost complete sequences, including the variable regions, were compared, the similarity values decreased slightly. The levels of $16 \mathrm{~S}$ rDNA sequence similarity between the type strain of Desulfotomaculum guttoideum and the type strains of $C$. celerecrescens and $C$. sphenoides are each $99.0 \%$. The DNA similarity of these three strains ranged between 73 and $78 \%$. In order to verify the authenticity of the type strain of Desulfotomaculum guttoideum, a new culture (strain VKM B-1591) was obtained from the original depositor, M. B. Vainshtein of Moscow, Russia, and a partial analysis of the 16S rDNA sequence of this organism was performed. Absolute sequence identity was found for the 5 '-terminal 350 bases, and strains DSM $4024^{\mathrm{T}}$ and VKM B-1591 should be considered identical.

Reinvestigation of some phenotypic properties revealed differences from the properties published in the original description of strain VKM B-1591 (17). In our experience, strain DSM
$4024^{\mathrm{T}}$ and newly received strain VKM B-1591 are fermentative and saccharolytic and reduce sulfite and thiosulfate, but they do not reduce sulfate. Desulfotomaculum guttoideum resembles $C$. sphenoides and $C$. celerecrescens in cell morphology (dropshaped versus wedge-shaped sporulating cells [unpublished data for the type strain of the latter species]), but the DNA base compositions differ by about $10 \mathrm{~mol} \%$. Reinvestigation of the DNA base compositions of the type strains of the three species by high-performance liquid chromatography revealed that these strains have similar DNA G + C contents $(42.7 \mathrm{~mol} \%$ for Desulfotomaculum guttoideum, $42.8 \mathrm{~mol} \%$ for $C$. celerecrescens, and $44.2 \mathrm{~mol} \%$ for $C$. sphenoides).

Taxonomic conclusions. The majority of Desulfotomaculum species form a phylogenetically homogeneous cluster that can be interpreted in terms of a genomically well-defined genus. On the other hand, the intersubcluster I 16S rDNA similarity values are as low as the levels of similarity found between several neighboring genera, some of which are shown in Fig. 1 (e.g., the genera Moorella and Thermoanaerobacterium, as well as the genera Selenomonas, Syntrophospora, Heliobacterium, and Desulfitobacterium). This raises the question of whether the subclusters could be treated taxonomically as individual genera. However, despite the differences in properties at the 16S rDNA level (levels of similarity, $\mathrm{G}+\mathrm{C}$ contents, structural features, signature nucleotides), very little phenotypic and molecular evidence is available $(2,3,24,30,44,46)$ that supports the dissection of the genus at this time. The phylogenetic 
clustering should encourage microbiologists to search for the presence of subcluster-specific properties that have diagnostic value and could be used in a future revision of the genus.

As judged from the $16 \mathrm{~S}$ rDNA similarity values, some of the undescribed Desulfotomaculum strains most likely represent novel species; two examples are strain DSM 7213 from freshwater mud and strain DSM 7440 from cooling tower water. The question of whether strain DSM 7574 and strains DSM 7475 and DSM 7476 (all from thermophilic fermentor sludge) are strains of Desulfotomaculum thermobenzoicum and Desulfotomaculum thermoacetoxidans, respectively, should be decided on the basis of the results of DNA-DNA hybridization studies. Physiological data are not available for these strains and are needed before a decision about taxon affiliation can be made.

Based on phylogenetic evidence, the following two Desulfotomaculum species should be excluded from the genus: Desulfotomaculum guttoideum, which shows high levels of relatedness to a cluster of Clostridium species ( $C$. sphenoides, $C$. celerecrescens, $C$. aerotolerans, and C. xylanolyticum), and Desulfotomaculum orientis, which clusters as a phylogenetic neighbor of the genus Desulfitobacterium. The observed phenotypic differences between the original description of Desulfotomaculum guttoideum and the results of tests performed with the deposited type strain of the species indicate that a careful reinvestigation of the taxonomic status of this organism must be performed. Because of the information available at this time, we do not present a formal proposal to reclassify Desulfotomaculum guttoideum as a species of the genus Clostridium. The taxonomic distinctness of Desulfotomaculum orientis led us to remove this species from the genus Desulfotomaculum and propose a new genus, the genus Desulfosporosinus, for this organism. The description of this genus below is based on previously published data $(2,3,19,24)$ and our own data.

Description of Desulfosporosinus gen. nov. Desulfosporosinus (De.sul.fo.spo.ro.si'nus. L. pref. de, from; L. n. sulfur, sulfur; M. L. n. spora, spore; L. n. sinus, bend; N. L. masc. n. Desulfosporosinus, a spore-forming curved [organism] that reduces sulfur compounds). Gram-negative, curved rod that has a multilayered cell wall structure. Endospores are produced; they are oval and subterminal and slightly swell the cells. Motile, with peritrichous flagella. Strictly anaerobic. Desulfoviridin and cytochrome $c_{3}$ are absent; bisulfite reductase $\mathrm{P}_{582}$ is present. Sulfate and thiosulfate are reduced to sulfide in the presence of lactate or pyruvate but not in the presence of acetate or fructose. Incomplete oxidation of organic compounds to acetate occurs. Autototrophic growth occurs with hydrogen plus sulfate. Homoacetogenic growth occurs with methanol and ethanol. Contains a menaquinone with a side chain having seven isoprene units (MK-7 type). The predominant fatty acids are even-numbered, saturated fatty acids (about $35 \%$ of the total fatty acids), unsaturated fatty acids (about 50\%), and aldehydes (about 15\%); iso- and anteisobranched fatty acids and cyclopropane fatty acids are absent.

The $\mathrm{G}+\mathrm{C}$ content of the DNA is 44.7 to $45.9 \mathrm{~mol} \%$. Phylogenetically a member of the Clostridium-Bacillus subphylum of gram-positive bacteria.

The type species is Desulfosporosinus orientis.

Description of Desulfosporosinus orientis (Campbell and Postgate) comb. nov. The description of Desulfosporosinus orientis is identical to that given by Campbell and Postgate (2) and Klemps et al. (24). The type strain is ATCC 19365 (= Singapore $\mathrm{I}=$ NCIB $8382=$ DSM 765).

\section{REFERENCES}

1. Brosius, J., M. L. Palmer, P. J. Kennedy, and H. F. Noller. 1978. Complete nucleotide sequence of the 16S ribosomal RNA gene from Escherichia coli. Proc. Natl. Acad. Sci. USA 75:4801-4805.

2. Campbell, L. L., and J. R. Postgate. 1965. Classification of the spore-forming sulfate-reducing bacteria. Bacteriol. Rev. 29:359-363.

3. Campbell, L. L., and R. Singleton, Jr. 1986. Genus Desulfotomaculum Campbell and Postgate $1965,361^{\text {AL }}$, p. $1200-1202$. In P. H. A. Sneath, N. S Mair, M. E. Sharpe, and J. G. Holt (ed.), Bergey's manual of systematic bacteriology, vol. 2. The Williams \& Wilkins Co., Baltimore, Md.

4. Collins, M. D., P. A. Lawson, A. Willems, J. J. Cordoba, J. FernandezGarayzabal, P. Garcia, J. Cai, H. Hippe, and J. A. E. Farrow. 1994. The phylogeny of the genus Clostridium: proposal of five new genera and eleven new species combinations. Int. J. Syst. Bacteriol. 44:812-826.

5. Cord-Ruwisch, R., and J. L. Garcia. 1985. Isolation and characterization of an anaerobic benzoate-degrading spore-forming sulfate-reducing bacterium, Desulfotomaculum sapomandens sp. nov. FEMS Microbiol. Lett. 29:325-330.

6. Daumas, S., R. Cord-Ruwisch, and J. L. Garcia. 1988. Desulfotomaculum geothermicum sp. nov., a thermophilic, fatty acid-degrading, sulfate-reducing bacterium isolated with $\mathrm{H}_{2}$ from geothermal ground water. Antonie Leeuwenhoek J. Microbiol. Serol. 54:165-178.

7. De Ley, J., H. Cattoir, and A. Reynaerts. 1970. The quantitative measurement of DNA hybridisation from renaturation rates. Eur. J. Biochem. 12: 133-142.

8. De Soete, G. 1983. A least squares algorithm for fitting additive trees to proximity data. Psychometrika 48:621-626.

9. Devereux, R., M. Delaney, F. Widdel, and D. A. Stahl. 1989. Natural relationships among sulfate-reducing eubacteria. J. Bacteriol. 171:6689-6695.

10. Devereux, R., and D. A. Stahl. 1993. Phylogeny of sulfate-reducing bacteria and a perspective for analyzing their natural communities, p. 131-160. In J. M. Odom and R. Singleton, Jr. (ed.), The sulfate-reducing bacteria: contemporary perspectives. Springer-Verlag, New York, N.Y.

11. DSMZ-Deutsche Sammlung von Mikroorganismen und Zellkulturen. 1993 DSM catalogue of strains, 5th ed. DSMZ-Deutsche Sammlung von Mikroorganismen und Zellkulturen, Braunschweig, Germany.

12. DSMZ-Deutsche Sammlung von Mikroorganismen und Zellkulturen. 1996. DSM catalogue of strains, supplement. DSMZ-Deutsche Sammlung von Mikroorganismen und Zellkulturen, Braunschweig, Germany.

13. Escara, J. F., and J. R. Hutton. 1980. Thermal stability and renaturation of DNA in dimethylsulphoxide solutions: acceleration of renaturation rate. Biopolymers 19:1315-1327.

14. Fardeau, M.-L., B. Ollivier, B. K. C. Patel, P. Dwivedi, M. Ragot, and J.-L. Garcia. 1995. Isolation and characterization of a thermophilic sulfatereducing bacterium, Desulfotomaculum thermosapovorans sp. nov. Int. J. Syst. Bacteriol. 45:218-221.

15. Felsenstein, J. 1993. PHYLIP (phylogenetic inference package), version 3.5.1. Department of Genetics, University of Washington, Seattle.

16. Fowler, V. J., F. Widdel, N. Pfennig, C. R. Woese, and E. Stackebrandt. 1986. Phylogenetic relationships of sulfate- and sulfur-reducing bacteria. Syst. Appl. Microbiol. 8:32-41.

17. Gogotova, G. I., and M. B. Vainshtein. 1983. The sporogenous sulfate reducing bacterium Desulfotomaculum guttoideum sp. nov. Mikrobiologiya 52: $789-793$.

18. Hagenauer, A., H. Hippe, and F. A. Rainey. 1997. Desulfotomaculum aeronauticum sp. nov., a sporeforming, thiosulfate-reducing bacterium from corroded aluminum alloy in an aircraft. Syst. Appl. Microbiol. 20:65-71.

19. Hippe, N., M. Vainshtein, and R. M. Kroppenstedt. 1995. Fatty acid composition and taxonomic significance in the genus Desulfotomaculum, poster no. PB082. In Spring Meeting of the Vereinigung für Allgemeine und Angewandte Mikrobiologie (VAAM), Stuttgart, Germany.

20. Huber, R., P. Rossnagel, C. R. Woese, R. Rachel, T. A. Langworthy, and K. O. Stetter. 1996. Formation of ammonium from nitrate during chemolithoautotrophic growth of the extremely thermophilic bacterium Ammonifex degensii gen. nov., sp. nov. Syst. Appl. Microbiol. 19:40-49.

21. Huss, V. A. R., H. Festl, and K.-H. Schleifer. 1983. Studies on the spectrophotometric determination of DNA hybridization from renaturation rates. Syst. Appl. Microbiol. 4:184-192.

22. Jahnke, K.-D. 1992. BASIC computer program for evaluation of spectroscopic DNA renaturation data from GILFORD SYSTEM 2600 spectrophotometer on a PC/XT/AT type personal computer. J. Microbiol. Methods 15:61-73.

23. Jukes, T. H., and C. R. Cantor. 1969. Evolution of protein molecules, p. 21-132. In H. N. Munro (ed.), Mammalian protein metabolism. Academic Press, New York, N.Y.

24. Klemps, R., H. Cypionka, F. Widdel, and N. Pfennig. 1985. Growth with hydrogen, and further physiological characteristics of Desulfotomaculum species. Arch. Microbiol. 143:203-208.

25. Love, C. A., B. K. C. Patel, P. D. Nichols, and E. Stackebrandt 1993. Desulfotomaculum australicum, sp. nov., a thermophilic sulfate-reducing bacterium isolated from the great Artesian basin of Australia. Syst. Appl. Microbiol. 16:244-251.

26. Maidak, B. L., N. Larsen, M. J. McCaughey, R. Overbeek, G. J. Olsen, K. 
Fogel, J. Blandy, and C. R. Woese. 1994. The Ribosomal Database Project. Nucleic Acids Res. 22:3485-3487.

27. Min, H., and S. H. Zinder. 1990. Isolation and characterization of a thermophilic sulfate-reducing bacterium, Desulfotomaculum thermoacetoxidans sp. nov. Arch. Microbiol. 153:399-404.

28. Nazina, T. N., A. E. Ivanova, L. P. Kanchaveli, and E. P. Rozanova. 1988 Desulfotomaculum kuznetsovii sp. nov., a new spore-forming, thermophilic, methylotrophic, sulfate-reducing bacterium. Mikrobiologija 57:659-663.

29. Nazina, T. N., and T. A. Pivovarova. 1979. Submicroscopic organization and spore formation in Desulfotomaculum nigrificans. Mikrobiologija 48:241-246.

30. Nazina, T. N., A. B. Poltaraus, and E. P. Rozanova. 1987. Estimation of genetic relationship between rod-shaped asporogenic sulfate-reducing bacteria. Mikrobiologija 56:669-672.

31. Nilsen, R. K., T. Torsvik, and T. Lien. 1996. Desulfotomaculum thermocisternum sp. nov., a sulfate reducer isolated from a hot North Sea oil reservoir. Int. J. Syst. Bacteriol. 46:397-402.

32. Rainey, F. A., N. L. Ward, H. W. Morgan, R. Toalster, and E. Stackebrandt. 1993. Phylogenetic analysis of anaerobic thermophilic bacteria: aid for their reclassification. J. Bacteriol. 175:4772-4779.

33. Rainey, F. A., N. Ward-Rainey, P. Janssen, H. Hippe, and E. Stackebrandt. 1996. Clostridium paradoxum DSM $7308^{\mathrm{T}}$ contains multiple $16 \mathrm{~S}$ rRNA genes with heterogeneous intervening sequences. Microbiology (Reading) 142: 2087-2095.

34. Rainey, F. A., N. Ward-Rainey, R. M. Kroppenstedt, and E. Stackebrandt. 1996. The genus Nocardiopsis represents a phylogenetically coherent taxon and a distinct actinomycete lineage: proposal of Nocardiopsaceae fam. nov. Int. J. Syst. Bacteriol. 46:1088-1092.

35. Saitou, N., and M. Nei. 1987. The neighbor-joining method: a new method for reconstructing phylogenetic trees. Mol. Biol. Evol. 4:406-425.

36. Sleytr, R., H. Adam, and H. Klaushofer. 1969. Die Feinstruktur der Zellwand und Cytoplasmamembran von Clostridium nigrificans, dargestellt mit Hilfe der Gefrierätz- und Ultradünnschnittechnik. Arch. Mikrobiol. 66:4058 .

37. Sproer, C., N. Ward-Rainey, F. A. Rainey, and E. Stackebrandt. Unpublished data.
38. Stackebrandt, E., D. A. Stahl, and R. Devereux. 1995. Taxonomic relationships, p. 49-87. In L. L. Barton (ed.), Sulfate-reducing bacteria. Plenum Press, New York, N.Y.

39. Strunk, O., and W. Ludwig. 1995. ARB-a software environment for sequence data. Department of Microbiology, Technical University of Munich, Munich, Germany.

40. Tanimoto, Y., and F. Bak. 1994. Anaerobic degradation of methylmercaptan and dimethyl sulfide by newly isolated thermophilic sulfate-reducing bacteria. Appl. Environ. Microbiol. 60:2450-2455.

41. Tasaki, M., Y. Kamagata, K. Nakamura, and E. Mikami. 1991. Isolation and characterization of a thermophilic benzoate-degrading, sulfate-reducing bacterium, Desulfotomaculum thermobenzoicum sp. nov. Arch. Microbiol. 155: 348-352.

42. Utkin, I., C. Woese, and J. Wiegel. 1994, Isolation and characterization of Desulfitobacterium dehalogenans gen. nov., sp. nov., an anaerobic bacterium which reductively dechlorinates chlorophenolic compounds. Int. J. Syst. Bacteriol. 44:612-619.

43. Vainshtein, M., G. Gogotova, and H. Hippe. 1994. A sulfate-reducing bacterium from the permafrost, p. 68-74. In D. Gilichinsky (ed.), Viable microorganisms in permafrost. Russian Academy of Science Pushchino Research Center, Pushchino, Russia.

44. Widdel, F., and T. A. Hansen. 1992. The dissimilatory sulfate- and sulfurreducing bacteria, p. 583-624. In A. Balows, H. G. Trüper, M. Dworkin, W. Harder, and K. H. Schleifer (ed.), The prokaryotes. Springer-Verlag, New York, N.Y.

45. Widdel, F., and N. Pfennig. 1977. A new anaerobic, sporing, acetate-oxidizing, sulfate-reducing bacterium, Desulfotomaculum (emend.) acetoxidans. Arch. Microbiol. 112:119-122.

46. Widdel, F., and N. Pfennig. 1984. Dissimilatory sulfate- or sulfur-reducing bacteria, p. 663-679. In N. R. Krieg and J. G. Holt (ed.), Bergey's manual of systematic bacteriology, vol. 1. The Williams \& Wilkins Co., Baltimore, Md.

47. Woese, C. R., R. Gutell, R. Gupta, and H. F. Noller. 1983. Detailed analysis of the higher-order structure of $16 \mathrm{~S}$-like ribosomal ribonucleic acids. Microbiol. Rev. 47:621-669. 